\title{
Maneuvers in Regional Flap Use in Reconstruction of Primary Defects in Head and Neck Cancer Patients: Presentation of Three Cases
}

\author{
Suha Nafea Aloosi
}

\begin{abstract}
This case series highlights the advantages in the use of three regional flaps, submental flap, sternocleidomastoid flap and transverse cervical flap in maxillofacial primary defect reconstruction after ablative cancer surgery through presentation of three head and neck cancer patients in whom it was decided to do pedicled flaps rather than free flaps.
\end{abstract}

Aim and objective: This article is done in an attemptfor encouraging for more introduction of these three flaps in head and neck reconstruction practice, and to encourage more studies be done to describe skin territory of cervical flap.

\begin{abstract}
Materials and methods: Three patients presented to oral and maxillofacial department, diagnosed as having different kinds of cancer. All were managed according to the evidence-based guideline of head and neck cancer management, including the work up, diagnosis, TNM classification, surgical treatment, adjuvant treatment and follow-up. In all the three cases, regional flaps were used to close the primary defect. For the first patient, transverse cervical flap was used, the sternocleidomastoid flap in the second and submental flap in the third one.
\end{abstract}

Results: All flaps were easy to be harvested, in term of time and technique, and successful in term of viability, extension and in achieving the functional and cosmetic aim of reconstruction, with minimum donor site morbidity, all the patient are enjoying good quality of life.

Conclusion and recommendations: The regional flaps have their place to overcome limitation of free flaps due to the shortage in the armamentarium available in the hospital, especially in low resources regions, or limitations related to patients general condition, in addition, regional flaps are the best option available in case of failed free flap, or when free flap failure is anticipated and avoided. Highlighting the different maneuvers in harvesting and using regional pedicled flaps for further extensions widens the scope of indications and giving the reconstructive surgeon variability of options in reconstruction, obviates the need for special microvascular expertise in free flaps with comparable results and relatively less complication.

Keywords: Lateral cervical, Sternocleidomastoid flap, Submental flap.

How to cite this article: Aloosi SN. Maneuvers in Regional Flap Use in Reconstruction of Primary Defects in Head and Neck

\footnotetext{
Surgeon

Department of Maxillofacial Surgery, Sulaimani University Kurdistan, Iraq

Corresponding Author: Suha Nafea Aloosi, Surgeon Department of Maxillofacial Surgery, Sulaimani University Kurdistan, Iraq, Phone: 009647701394101 , e-mail: suha_ aloosi@yahoo.com
}

Cancer Patients: P resentation of Three Cases. Int J Head Neck Surg 2014;5(1):48-55.

Source of support: Nil

\section{Conflict of interest: None}

\section{INTR ODUCTION}

The reconstruction of oral and maxillofacial primary defect following cancer surgery has a significant impact on quality of life of cancer patients.

The first breakthrough in head and neck reconstruction come with the development of the pedicled regional musculocutaneous flaps that do not require delay procedure and permit the transfer of muscle and skin to various parts of head and neck in single stage, ${ }^{1}$ since that time, many regional flaps are made available so far for the reconstructive surgeon, nevertheless, all have their short comings. ${ }^{2}$

F ree flaps are considered as an extension for the principles on which the pedicled flaps are based, and the fast development in instrumentation and surgical techniques lead to widespread application of free tissue transfer ${ }^{1}$; however, still there is a wide place for regional flaps in the reconstruction practice.

\section{MATERIALS AND METHODS}

Three patients of head and neck cancer where presented to the Maxillofacial Department in the Teaching Hospital of Sulaimani U niversity, diagnosed as having different kinds of cancer. A Il were managed according to the evidence based guide line of head and neck cancer management including the work up, diagnosis, TNM classification, surgical treatment, adjuvant treatment and follow-up. In all the three cases, regional flaps were used for reconstruction.

\section{CASE REPORTS}

\section{Case 1}

A male patient of 38-year-old was diagnosed as having dermatofibrosarcoma protuberance in the cheek (Fig. 1A) invading the underlying muscles, work up done. The tumor was classified as $\mathrm{T} 2 \mathrm{~b}$ N $0 \mathrm{M} 0$, according to sarcoma classification, the treatment options was explained carefully. The surgery was done under frozen section histopathology examination guide done while the surgery in progress, 
2 to $3 \mathrm{~cm}$ was decided to be taken to guarantee safe margin (Fig. 1B).

The tumor extended in depth to reach the oral mucosa, lymphadenectomy was done electively. The muscle of the face and the mucosa of the cheek was reconstructed by pectoralis major myocutaneous flap (Fig. 1C), then the transverse cervical flap was elevated, based on wide base, used to resurface the skin defect of the cheek, the skin of the neck was closed partially by approximation, and the other part (most lower) by split thickness skin graft (Fig. 1D), the patient then received concurrent chemoradiotherapy, after the completion of the treatment (Fig. 1E). Notice the gradual disappearance of the dog ear which is usually formed after reconstruction by transverse cervical flap.

\section{Case 2}

The second patient was a 26-year-old male presented with sizeable mass in the preauricul ar region (Fig. 2A ) involving deep lobe of parotid, masseter muscle, ramus of mandible diagnosed as low grade osteogenic sarcoma, the work-up was done, clinical and radiological examination done, in spite of the muscle and part of the parotid were involved (Fig. 2B ), the facial nerve was intact by clinical and radiological examination. The tumor was classified as T2 N 0 M 0 according to TNM classification of sarcoma of bone, the thorough explanation of the treatment plan and counseling of the patient done, the patient treated surgically by excision of the mass and the involved structures with soft and hard tissue safe margin through parotidectomy incision, total parotidectomy, in addition to whole ramus resection and disarticulation was done, the involved muscle was also resected, all branches of facial nerve were saved, neck was dissected electively, and the sternocleidomastoid muscular flap was elevated and applied below the branches of the facial nerve to fill the defect and protection of facial nerve (Figs $2 \mathrm{C}$ and $\mathrm{D}$ ), patient received adjuvant chemotherapy (cisplatin and doxorubicin) after healing period, the patient was satisfied by the results and enjoying good quality of life.

\section{Case 3}

The last patient in this series is a 85-year-old male presented with $5.5 \mathrm{~cm}$ mass involving the dorsum of tongue (Fig. 3A) diagnosed as squamous cell carcinoma. Work-up of the case was done, the neck was not involved clinically or radiologically. The tumor was classified as T3 NO M 0 and the treatment plan was explained to the patient and to the family. The major concern of the patient was the quality of speech function. The surgery included glossectomy and elective neck lymphatic clearness and reconstruction of the primary tongue defect. The first plan was to reconstruct the primary defect after partial glossectomy by radial free forearm flap, but the Allen's test done on preoperative day was not encouraging, so the submental flap was a good option, and the elevation of the flap took 35 minutes (Fig. 3B). The patient received radiotherapy postoperatively. The patient is quite satisfied by the result (Figs $3 \mathrm{C}$ and D), enjoying good quality of speech and swallowing function.
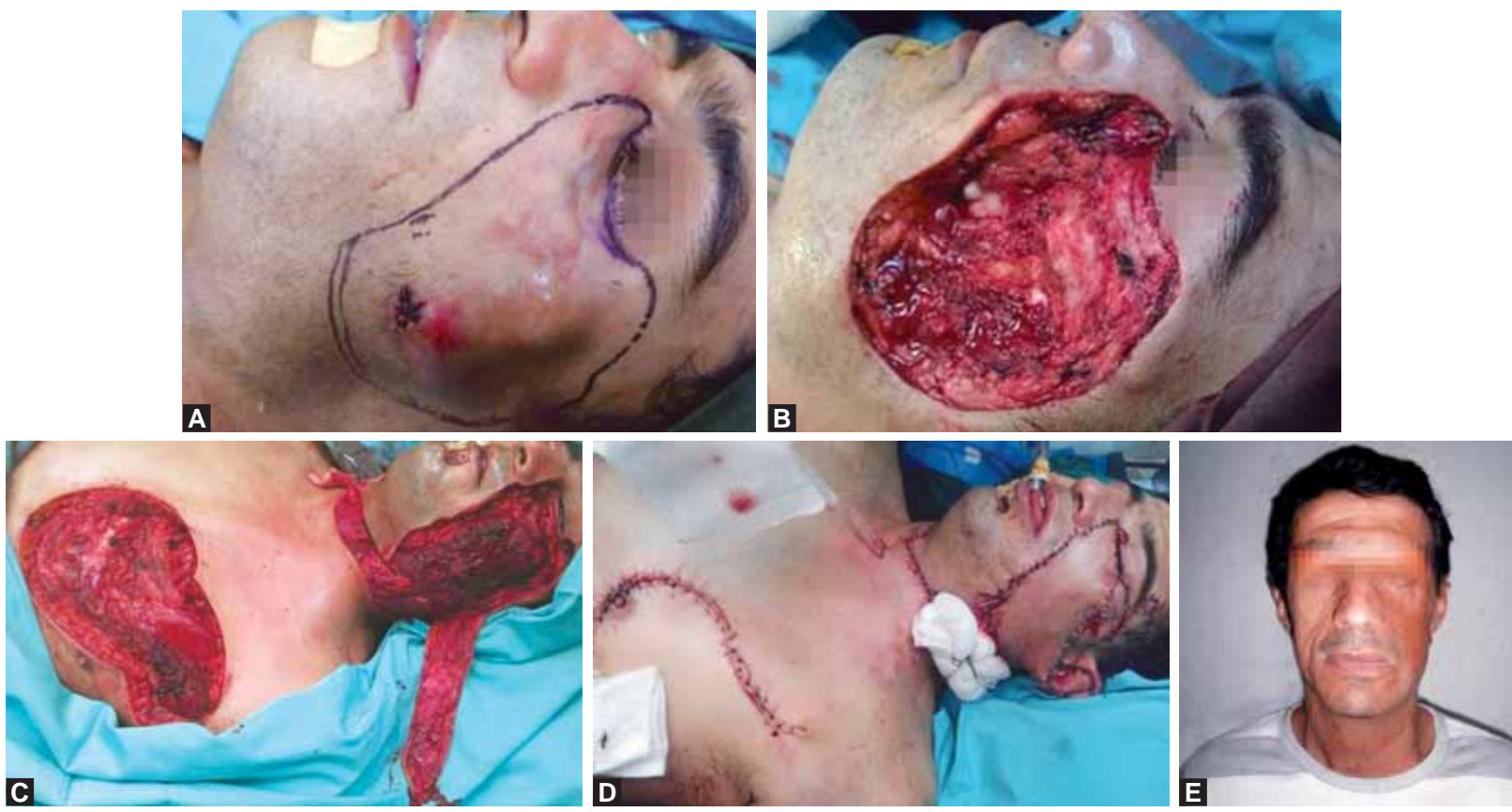

Figs 1 A to E: (A) The tumor, dermatofibrosarcoma protuberance, marked primarily, futher excision guided, by frozen section hisopathological exam, (B) the through and through defect size, $(C)$ the muscles of the face and the oral mucosal defect closed by pectoralis major myocutaneous flap and the transverse cervical flap is elevated, (D) the transverse cervical flap sutured in the recipient site, the donor site was closed primarily and partially by skin graft and (E) the patient after completion of chemoradiotherapy 


\section{DISCUSSION}

\section{Cervical Flap}

Regional cutaneous flaps are readily available, and under selected circumstances may still be considered option for immediate reconstruction in head and neck area $^{3}$ and a very good example is the cervical flap.

Cervical flap was designed to make use of the lax skin of the neck for different reconstruction purposes; it can be used to close defects in face and neck, and maybe used intraorally to close defects of modest dimension. ${ }^{3}$ I t is a reliable source of skin of excellent color and texture matching for facial resurfacing and very simple for harvesting, the donor site can be closed primarily; skin graft may be needed if a large flap is harvested. Some authors consider it as axial cutaneous flap ${ }^{4}$, by others as random ${ }^{3}$ and other consider it as empirically designed. It can be swung on differently based pedicle, posterior, superior or even anterior and so oriented vertically or transversely.

If the anterior aspect of the neck is used it is called anterior cervical flap, and if the lateral aspect of the neck is used it is called lateral cervical flap ( $\mathrm{K}$ ummoona flap) ${ }^{5,6}$ which is modification of platysma flap (myocutaneous), and if the posterior aspect of the neck is used it is called posterior cervical flap (M utter flap), and according to Shah, if the cervical flap is transversely oriented (which is the flap used in this presentation) is considered as random, and the length of which can be elevated with ease and without compromising the blood supply is limited, and generally is not more $1: 3$ width to length ratio. ${ }^{3}$ Being 'random' in its pattern, this flap is not usually recommended to reconstruct large skin defect, but in this case it was used to fill a large facial defect with very satisfactory result, specially the color matching.

It is interesting to notice that in most of the time, the suggestion or recommending this particular flap design or another is based on a mixture of clinical experience with anatomical knowledge rather than a vasculature pattern studied thoroughly, It is not only the anatomical territory of a flap that matters, it is the dynamic and the potential territory that makes the flap viable, in fact, many flaps are successful although theoretically the flap exceed the ability
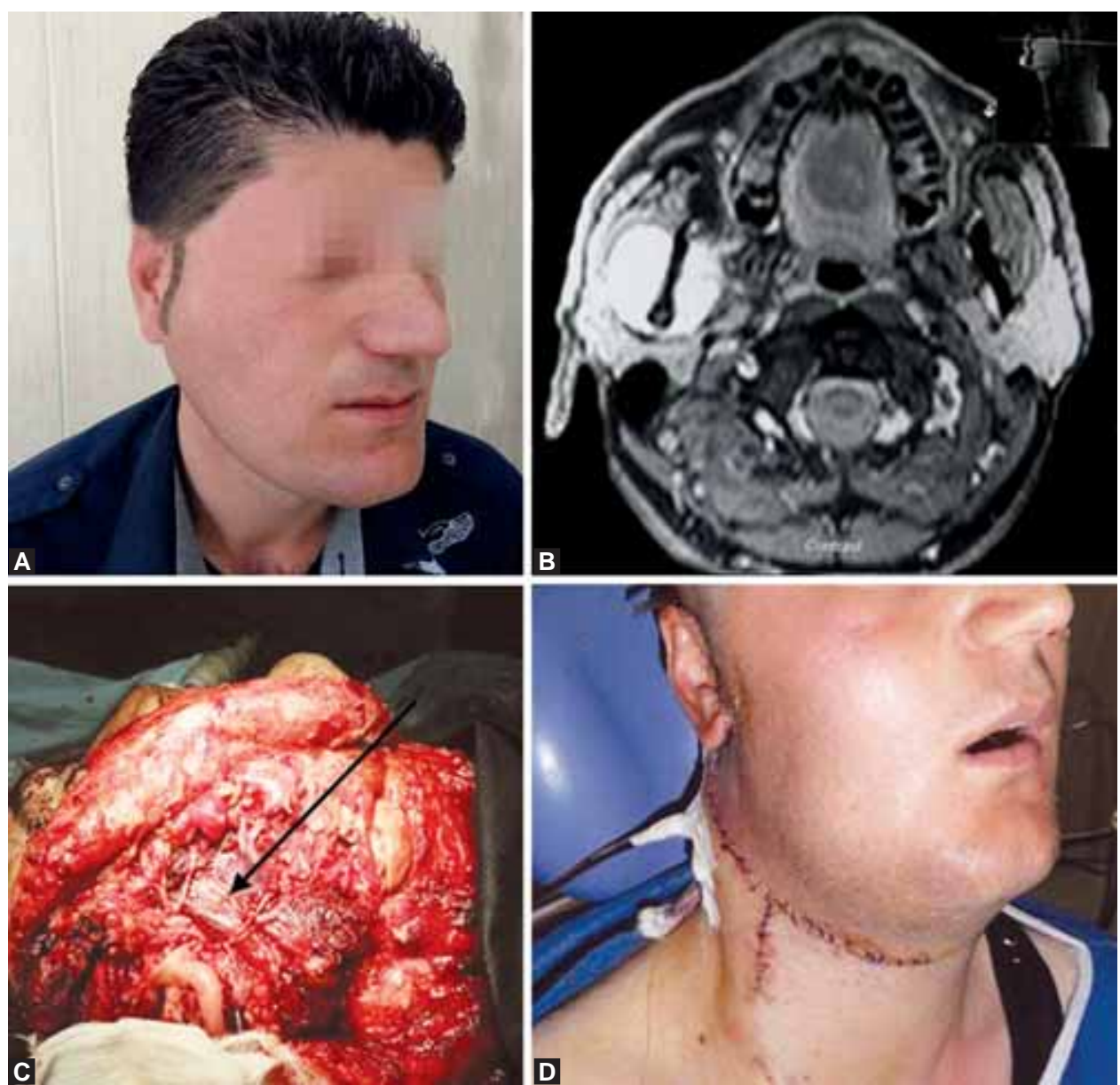

Figs 2A to D: (A) The patientwith the swelling in rightpreauricular area atpresentation, (B) CT scan with contrastshows the mass 'osteogenic sarcoma' involving the mandible invading the masseterand the deep parotid tissue, (C) the black arrow pointing atthe sternocleidomastoid muscle positioned in the recipient site below the branches of facial nerve after total parotidectomy and mandibular ramus resection and (D) the patient on first postoperative day 
of its particular anatomical territory. The artery supplies any anatomical territory is called the prop, and the area supplied is called angiotome, any additional territory will be supplied in a more random fashion and is called dynamic and potential territories. The potential territory incorporates the random element of the flap, and this is the part that undergoes a fundamental change during the period between the delay of the flap and the elevation. This will change the vascularity type from random to axial. ${ }^{7}$

Skin (cutaneous) flaps receive their blood supply through horizontal component which is subdermal and prefascial plexus. The prefascial plexus lies on the deep fascia and distribute blood to the skin. This plexus can be located in a similarly placed structure like platysma in the face in some parts of the body where there is no deep fascia.

The vertical component are the perforator vessels arises from deeper arteries and veins, anastamosing with the prefascial plexus and connect it to the subdermal plexus. ${ }^{8}$

When some intervention take place like harvesting a flap, there will be a resultant alteration in the intravascular pattern and change in the dynamic equilibrium leading to readjustment in the flow and change in the area perfused. ${ }^{7}$ This may be happened in cervical flap. The perforators included in flap will usually, reliably supply the skin in its own territory and that of the adjacent perforator, and beyond this the blood supply is doubtful. ${ }^{7}$ This is the concept of watershed based on the work of $\mathrm{M} \mathrm{CG}$ regor and M organ $1973 .{ }^{9}$

In fasciocutaneous flap, the perforators designs are four types, the success of the cutaneous part depend on the axiality of the perforators from the fascia to the subdermal plexus. ${ }^{7}$ The axiality of the perforators in the cervical flap is not known yet. For a flap like cervical flap, the fascia is almost al ways included, so the prefascial plexus is elevated with the flap, means the blood supply should have been augmented and this flap can be larger and safer if they would include the perforators, and this is the justification of a recommendation to include the platysma in the flap.

The vascular network between the platysma and the skin and that the muscle and the superficial fascia in the anteriolateral skin of the neck serve as scaffolding for the vessels is vital in mapping the cervical flap. In a study done by DJ Hurwitz et al 1983, the platysma and the overlying skin are supplied by direct cutaneous branches, from posterior auricular and occipital artery in the upper lateral area, facial and the submental artery in the upper medial,
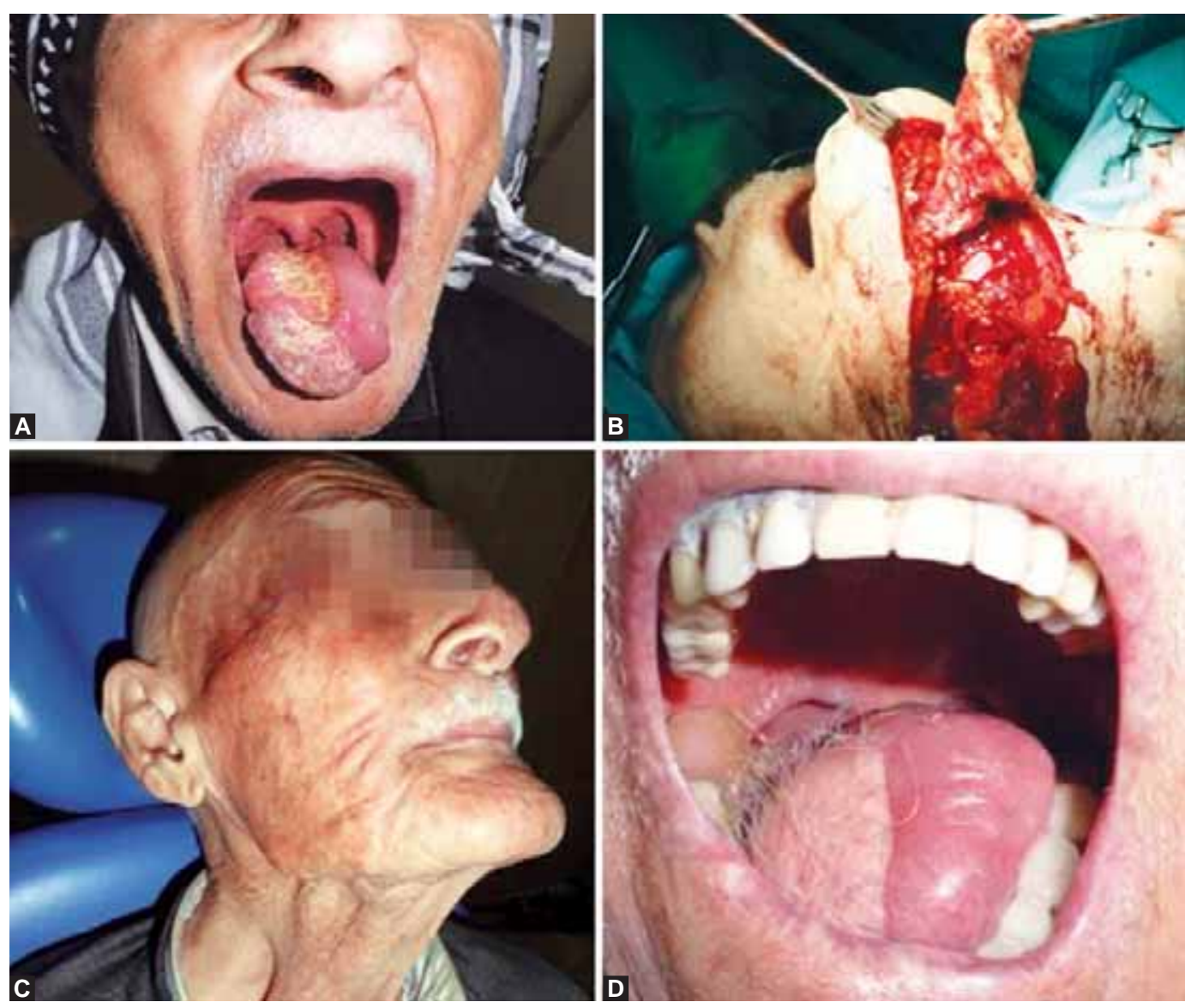

Figs 3A to D: (A) Patient at presentation with large mass on the dorsum of the tongue provided to be SCC by histopathological exam, (B) the submental flap raised about $10 \mathrm{~cm}$ in length and the pedicle is skeletonized, (C) patient after 1 month postoperative with minimum scar, hidden below the mandible and (D) the tongue with the dorsum and the right lateral border reconstructed by the flap, notice the hair grows on the flap 
superior thyroid in the middle of the neck, subclavian in the lower medial, and the transverse or the superficial cervical artery in the lateral aspect of the neck. These vessels transverse the undersurface of the platysma to provide blood supply to the skin and, therefore, it should be elevated with the skin during neck dissection. ${ }^{10}$ These vessels were described as having vertical orientation, and this makes us think that both the axial and the random pattern of blood supply in cervical flap should be considered and neck dissection dose not preclude the use of this flap as the platysma is always elevated with the neck dissection flap. A very important conclusion for their study, is that the platysma skin flap will survive, if the blood supply from at least one artery is preserved. ${ }^{10}$

A very interesting radiological study done by Rogers $\mathrm{JH}, \mathrm{F}$ reeland AP, showed that there is a net work of small vessels between the platysma and the skin of the cervical flap originating from the external carotid artery superiorly and the subclavian artery inferiorly and that there is a distinct watershed between these two arteries, and they recommended the inclusion of the platysma during el evation of the flap and that the flap that the horizontal limb of the flap should include the watershed area, the richest blood supply lies superiorly, and the upper flap should be larger than the lower flap. ${ }^{11}$ A ccording to ${ }^{10}$ the platysma muscle supplies blood to the skin, and should be included in the flap elevated during neck dissection. the platysma inclusion in the flap should be considered in big defects with guarantee to plan it on a wide base to include one or two pedicles (submental, posterior auricular, occipital arteries, so by this, we can extend the length of the flap beyond 1:3 ratio.

Till now, still there is general dissatisfaction among the reconstructive surgeons regarding the classification of flaps, and not uncommonly is described as being 'old fashion', and regarding the cervical flap there is no clear classification whether it is cutaneous, fasciocutaneous or muscular flap. By good observation of the flap, it is usually elevated with the superficial fascia of the neck and not uncommonly with the platysma muscle, and even during neck dissection surgery with variable degrees of success rate, which make it fasciocutaneous or myocutaneous, and one should state here that some axiality is actually inherited in this flap. Including the platysma in the cervical skin flap has the advantage of providing beautiful bulk and texture to the flap, it was advised to preserve the vascular network between the platysma and the skin ${ }^{10}$ and although this maneuver was possible and successful in our practice like in the case presented (case 1), and by the practice of many surgeons, whether the including the platysma in the cervical skin flap will increase the success rate and enable the flap to be used to reconstruct bigger defects or to cross multipl e anatomical territories is not confirmed. A nd until that time, principles of both random and axial pattern of flaps should applied when harvesting the cervical flap.

Deltopectoral (B akamjian) flap is always described as an axial cutaneous flap depending on the perforators in its proximal part, and in its distal part it is random depending on the continuity of the subdermal plexus of the donor, ${ }^{12}$ it seems now that there is much similarity between deltopectoral flap and transverse cervical flap in that both axial and random pattern are inherited in it, so delay technique can be useful when larger flap is need.

Elevation the cervical flap, to cross many anatomical territories, necessitate that the flap should consist of musculoskeletal perforators, or the fasciocutaneous perforators to anastomoses the direct cutaneous vessels or the plexus in the same level and not on different anatomical level, if the flap will relay in anastamoses on different levels, they will not be capable to cross different anatomical territories, ${ }^{7}$ and this need further studies. Planning the flap on a wide base, inclusion of platysma, inclusion of the watershed area, all are points to be remembered in elevation of transverse cervical flap. Considering the delay technique is another option when longer flap is needed like when constructing upper face defect.

\section{Sternocleidomastoid Flap}

Sternocleidomastoid (SCM) flap covers the anterior neck, posterior neck, lower face, midlateral face, oral cavity and occipital scalp, also used in reanimation and even to reconstruct mandible according to $\mathrm{M}$ athes and $\mathrm{N}$ ahai ${ }^{12}$ and, in case 2 in this series, it was used to fill the defect created by resection of the ramus of mandible (Fig. 2). The use of SCM muscle in head and neck reconstruction has been restricted because of the presumed difficulty in preserving its blood supply. The necrosis of the flap due to insufficient perfusion, ${ }^{13,14}$ in addition, the muscle is considered as an area of oncological significance in cancer patients, however, SCM flap is still used by many surgeons having the hypothesis that the flap is practicable and can be a reliable alternative if free flap is not possible. Different types of SCM flap are in the practice.

The SCM flap was first described by Jianu $1909^{15}$ and used to reconstruct mandible, floor of mouth or to close a pharyngoesophageal, tracheal fistula. The applications of the muscle flap involved prevention of Frey's syndrome, closure of orocutaneous fistulae and soft tissue deficiencies, closure of pharyngocutaneous and cervical esophageal fistulae and reconstruction of the tongue. Furthermore, Conley reported on the use of the SCM muscle flap to reanimate the face, reconstruct oral cavity defects, protect the carotid and innominate artery, and even to aid shoulder 
elevation after poliomyelitis ${ }^{16}$ it also can offer a major vessels protection after radical neck dissection and help to prevent F reys syndrome and to provide fullness after parotidectomy with good cosmetic result.

It can be elevated and based on dominant pedicle, the lower two third of the muscle can be rotated anteriorly, or posteriorly, or based on the distal pedicle to cover middle or lower part of the neck. The lower skin paddle overlying the distal part of the muscle can be el evated to cover an intraoral defect, but this skin paddle is considered poorly viable. ${ }^{12}$

The failure rate reported in the literature varies, due to variety of applications for SCM flap in practice which makes the comparison difficult, $M$ arx and $M$ cdanald ${ }^{17}$ reported a failure rate of $25 \%$ if the SCM flap was used as muscular or myocutaneous flap but, according to his metaanalysis, K ierner et al reported only one major complication (necrosis), and seven minor complications (total of $11 \%$ ) out of 72 SCM flap used as muscular flap. They also reported in their literature review a 21\% (29 out of 138 patients) failure rate if the flap was taken as myocutaneous version with partial skin necrosis was the most frequent, seven flaps showed total failure, flap necrosis was reported in one patient $(4 \%)$ out of 23 osteomuscular SCM flap. ${ }^{18}$

Siemsson et al reported one failure out of 18 splitted clavicular head of SCM used to repair laryngeal and tracheal defects leaving the sternal head ${ }^{19}$ and, according to Watkinson JC et al, the flap is rarely used now, but it may still have a role to play filling small defects in pharynx and oral cavity, and to cover vessels in the compromised neck. ${ }^{4}$

According to a blood supply cadaveric study done by Kierner et $\mathrm{al}^{20}{ }^{20}$ he had a general agreement that the blood supply of the SCM comes from 3 main arteries described in other main studies, ${ }^{16,21}$ for the upper third it is supplied mainly by occipital artery which is further divided into 3 categories smaller upper branches representing $87 \%$, and a single well-developed branch on 33 to $39 \%$, this branch goes with the accessory nerve in 19 to $27 \%$, for the middle third blood supply, the study shows some variability, it concluded that about $50 \%$ of cases are supplied directly by the external carotid artery, and in 67 to $71 \%$ have branches from superior thyroid artery, and in more than $80 \%$ of cases, the lower third of the muscle is supplied by suprascapular artery. Tivari considered the occipital artery as the major blood supply, agreed with L arson and Goepfert results. 22,23

A ccording to this simple review of the blood supply of this muscle in the literature, the clinician may increase the success rate of his sternocleidomastoid flap, in addition, the flap can be extended by releasing the attachment of the muscle on the mastoid, so increasing the arch of rotation, ${ }^{12}$ and the point that we want to emphasize here is the flap can be extended by this way without compromising the blood supply, and this was based on two points, first, according to the many studies, the main blood supply is the occipital artery and the superior thyroid artery and that the posterior auricular artery is only a minor pedicle. ${ }^{20}$

The second point is that both occipital artery and superior thyroid artery emerge from the external carotid artery from anterior medial side ventrally to the muscle, and give many small branches penetrating the muscle somewhere from anterior margin to continue posteriorly. ${ }^{16,20,21}$ So, the safest way to elevate the muscle is to start dissecting the muscle with its fascia from posterior margin to anterior protecting the pedicle and the accessory nerve.

The occipital artery and the superior thyroid artery should be identified and protected as they branch from the external carotid artery, inferior separation of the needed length of the muscle is performed till the origin of the superior thyroid artery, near the bifurcation, considering this point as the arc of rotation and that no further superior dissection is without danger on the flap.

\section{Submental Flap}

Disturbance of tongue function resulted from the involvement by a neoplasm, has a very drastic impact on patient quality of life by affecting the patient oral physiology. The tongue is initially important in both oral and pharyngeal phase of deglutition and in prevention of aspiration, manipulation of food bolus for successful mastication and maintenance of oral hygiene, largely responsible for articulation in addition in its function of feedback by taste fibers and sense of texture of food. Functions of mobile tongue differs from those of tongue base, the disturbance in function of mobile tongue affects the patients ability to chew, propel food, maintain oral hygiene and articulation, and this will have an impact on patient diet and social interaction ${ }^{1}$ and in general, a poor qual ity of life, which is now the overwhel ming parameter for assessing success of different treatment and reconstruction modalities, specially in cancer patients. W ith exception of free flaps, there is not very much satisfactory flap for reconstruction of intraoral primary defect after cancer surgery specially floor of mouth and tongue defects.

The radial free forearm flap use in head and neck reconstruction is one of the workhorse for oral cavity defect reconstruction options, providing pliable skin which suitable for three-dimensional defects reconstruction particularly in oral cavity. ${ }^{4}$ Local flaps available may include, lateral cervical flap, platysma flap, nasolabial flap, but all are of limited mobility specially for the tongue, and leave a conspicuous donor site. M any requirements are needed in reconstruction of primary defect in the oral cavity, it should be reliable good bulk and texture, good mobility to restore the function of speech and swallowing if tongue and floor of mouth need to be reconstructed, these requirements can be met by submental flap. ${ }^{24}$ 
Submental flap described first by M artin $1993,{ }^{25}$ is an island flap, first used to reconstruct oral defect was by Sterne $1996,{ }^{26}$ it is very good for reconstruction of intraoral primary defects, it is an axial flap and it is reliable, gives good contour and leaves hidden donor site, it is simple and rapidly elevated with relative ease and it overcomes the problem and the disadvantages of limited mobility and donor site morbidity of other local flaps, the high reach gives it the advantage of crossing and reconstructing distant and multiple anatomical territories like cheek, and provide good quality of functions, like speech and swallowing, when used to reconstruct tongue and floor of mouth.

Submental flap is an axial flap, depends in its blood supply on the submental artery which is a branch of the facial artery, and drains by the submental vein in, which in turn drains into the common facial vein. ${ }^{25}$ The flap is raised in antrograde or in retrograde fashion, the pedicle length reaches $5 \mathrm{~cm}$ by skeletonizing the pedicle, further extension can be added by ligating the distal portion of the facial artery after giving off the Submental artery. ${ }^{24}$ The flap used to reconstruct intraoral defect is elevated in antrograde fashion with good reach and do not usually necessitate the maneuver of ligation the distal part of the facial artery. When the flap is elevated in retrograde fashion, the proximal part of the facial artery can be ligated with the corresponding vein and here it may cross a distant anatomical territory to reach infraorbital region. ${ }^{26}$

$M$ any authors have recommend the use of this flap for small to moderate defect ${ }^{24}$ actually he did not recommend it for a lesion more than $5 \mathrm{~cm}$ which logically would leave larger primary defect when excised with safe margin. A ccording to the classification of the defect based on the size made by $M$ athes and $N$ ehai, ${ }^{27}$ a defect of $4 \mathrm{~cm}$ is considered small, up to $7 \mathrm{~cm}$ is moderate and and more than $7 \mathrm{~cm}$ is large defect, in the case presented here, the tongue defect was more than $8 \mathrm{~cm}$ created after excision of T3 mass of squamous cell carcinoma, reconstructed with submental flap with good quality of speech and swallowing. A ccording to $M \operatorname{artin}^{25}$, the size of the flap can be increased to $15 \times 6 \mathrm{~cm}$.

The tongue should be reconstructed regarding a very well-known parameters which include mobility, sensation, taste sensation, volume, shape, position and mucosal lining, ${ }^{28}$ unfortunately, tissue reconstruction can not usually met perfectly all these parameters. It is vital to adopt the current concept of defect oriented approach strategy for classification and reconstruction of different types and sizes of tongue defects mapped by U rken et al (1991) and modified by U rken and 0 kay. ${ }^{29}$ The reconstruction options for tongue after partial or total glossectomy ranges from healing by secondary intention, primary closure, tongue flap, skin graft, regional flaps, and free flap this ranges with the size and type of the defect.
A ccording to U rken and Okay, the overall principles in the concept of defect oriented approach for reconstruction is that the surface area, volume and redundancy should be the goal, achieving maximum tongue mobility through the use of redundant thin pliable tissue, specially in class 2 , and 4 . In class 2B, 2C, 3, 4 and 6, the issue of volume take on the paramount importance ${ }^{29}$ and in cases of tongue tumor and floor of mouth, where substantial bulk of the tongue and floor of mouth may be removed, it is mandatory to reconstruct this tissue with sufficient bulk, restoring the volume and allows good mobility of the tongue needed in function of speech and swallowing, we think that submental flap is a good option to reconstruct a substantial tongue defects including class $2 \mathrm{~A}, 2 \mathrm{~B}, 2 \mathrm{C}$ and $3 \mathrm{~A}$, and unilateral class 4 and floor of mouth defect and it is a good alternative for radial forearm free flap when the later is not possible or as salvage flap after free flap failure.

The issue of oncological safety is still controversial, many authors cautioned against the use of the flap in oral cancer, the caution is explained by the proximity of level I (submental and submandibular lymph node) to the flap and to the flap pedicle. ${ }^{25,26,30}$ Stern, in his study ${ }^{26}$, reported that this flap should be carefully considered in patients with positive lymph nodes because of a potentially involved lymphatics may be left in the flap but he is recommending the flap in cases when only prophylactic clearness is indicated. The risk of nodal metastasis and the difficulty in cleaning level I lymph node was a concern to many surgeons. A ccording to Sabastian et al, in their study, a total of 30 patients underwent reconstruction by submental flap for different anatomical territories in face and oral cavity, and although all of those patients had therapeutic or prophylactic neck dissection, they reported three cases of recurrence, and they are not recommending the flap for patients with palpable or radilogically demonstrated lymph node. ${ }^{24}$

Platysma and the skin are usually elevated with the flap in neck dissection, none of them are indicated to be removed during nodal clearness even in pal pable level I, neither the blood vessels or the digastric muscle is indicated to be excised in such condition. Involvement of level I by the disease increases the possibility of inclusion of lymphatic tissue carrying malignant cells into the flap. ${ }^{30}$ Careful removal of all lymphatic tissue is carried out and thinning of the flap is recommended in such cases $^{24}$ and for patients treated previously by neck dissection, it is better to harvest the flap pedicled on the contra lateral submental artery and vein, for that the vessels in the dissected side may have been injured in the previous surgery. ${ }^{24}$

The second point is that the skin of the submental area is hairy, specially in male patient, and hair grows inside the oral cavity causes sever of discomfort. Continuous 
epilation of hair is considered before the environmental changes makes this problem only temporary. In addition, for most of the cases, radiotherapy is going to be recommended as adjuvant treatment modality of cancer and this will alleviate this problem.

\section{CONCLUSION AND RECOMMENDATION}

The regional flaps have their place to overcome limitation of free flaps due to the shortage in the armamentarium available in the hospital or limitations related to patients general condition for that the free flap requires more time for harvesting and anastamosing, in addition, regional flaps are the best option available in case of failed free flap, or when free flap failure is anticipated and avoided.

Highlighting the different maneuvers in harvesting and using regional pedicled flaps for further extensions widens the scope of indications and giving the reconstructive surgeon variability of options in reconstruction, obviates the need for special microvascular expertise in free flaps with comparable results and rel atively less complication, specially in low resources regions.

Each one of the three flap presented in this case series has a very unique property, the ease to be elevated, the beautiful texture and color matching the face, and the hidden donor site for transverse cervical flap, the good bulk and less morbidity in covering wide ranges of defects in different territories for the SCM flap, and the short time needed, with high reach and mobility to reconstruct tongue defect with minimum morbidity for the submental flap. A nd, good knowledge in anatomy and in the details of the technical steps provides more opportunity for the patient to benefit from these advantages of these flaps aiming for best quality of life.

\section{REFERENCES}

1. Urken ML. Multidisciplinary head and neck reconstruction. A defect-oriented approach. Wolters K luwer, Lippincott Williams $\&$ Wilkins 2010, Introduction (px).

2. Vural E, Suen JY. The submental island flap in head and neck reconstruction. Head N eck Surg 2000;22:572-578.

3. Shah JP, Patel SG. Head and neck surgery and oncology. M M osby. 3rd ed. 2003, Chapter 15, p. 593-597.

4. Watkinson J C, Gaze M N, Wilson JA. Stell and M arans head and neck surgery. Butterworth-Henemann 2000;7:101-157.

5. Kummona R. U se of lateral cervical flap in reconstruction surgery of orofacial region. In J Oral M axillofac Surg 1994;23:85-89.

6. Kummona R. Reconstruction by lateral cervical flap of perioral and oral cavity: clinical and experimental study 2010;3:21.

7. Cormack GC, George B, Lamberty $H$. The arterial anatomy of skin flaps. Churchill Livingstone 1994;8-13.

8. Penington A J . Local flap reconstruction. A practical approach. The M cGraw-Hill A ustralia, Pty Ltd. 2007. p. 14.
9. M cG regor IA, M organ G. A xial and random pattern flap. B ritish J ournal OD Plastic Surgery 1973;26:202-213.

10. Hurwitz DJ, Rabson JA, Futrell JW. The anatomic basis for the platysma skin flap. Plast Reconstr Surg 1983 Sep;72(3): 302-314

11. Rogers $J H$, Freeland AP. A rterial vasculature of cervical skin flaps. Clinic Otolaryngol Allied Sci 1976;1(4):325-331.

12. M athes SJ , N ahai F. R econstruction surgery, principles, anatomy and technique. Churchill Livingstone 1997:355-424.

13. Larson DL, Goepfert H. Limitations of the sternocleidomastoid musculocutaneous flap in head and neck cancer reconstruction. Plast Reconstr Surg 1982; 70:328-335.

14. Friedman $M, M$ ayer $A D$. Laryngotracheal reconstruction in adults with the sternocleidomastoid myoperiosteal flap. Ann Otol Rhinol Laryngol 1992;101:897-908.

15. JianuJ. Diechirurgische behandlung der facialislähmung. Deutsche Z Chir 1909;102:377-386.

16. Conley J, Gullane PJ. The sternocl ei domastoid muscle flap. Head Neck Surg 1980;2:308-311.

17. Marx RE, M CDonald DK. The sternocleidomastoid muscle as a muscular or myocutaneous flap for oral and facial reconstruction. J Oral M axill ofac Surg 1985;43155-43162.

18. K ierner AC, Zelenka I, Gstoettner W. The sternocleidomastoid flap-its indications and limitations. The laryngoscope 2001;111:2201-2204.

19. Siemssen $\mathrm{SO}, \mathrm{K}$ irkby $\mathrm{B}, \mathrm{O}^{\prime}$ Connor TPF. Immediate reconstruction of a resected segment of the lower jaw using a compound flap of clavicle and sternomastoid muscle. Plast Reconstr Surg 1978;61:724-735.

20. Kierner A C, Aigner M, Zelenka I, Riedl G, Burian M. The blood supply of the sternocleidomastoid muscle and its clinical implications. A rch Surg 1999;134(2):144-147.

21. Williams PL, Warwick R, Dyson M, Bannister LH. Gray's A natomy. 37th ed. London, England Churchill Livingstone 1989;583f.

22. Tivari R. Experiences with the sternocleidomastoid muscle and myocutaneous flaps. J Laryngol Otol 1990;104:315-321.

23. L arson DL, Goepfert H. L imitations of the sternocleidomastoid musculocutaneous flap in head and neck cancer reconstruction. Plast Reconstr Surg 1982;70:328-335.

24. Sebastian $P$, Thomas $S, V$ arghese $B T$, et al. The submental island flap for reconstruction of intraoral defects in oral cancer patients. Oral Oncology 2008:44:1014-1018.

25. M artin D, Pascal J F, B audet J, et al. The submental island flap: a new donor site. A natomy and clinical applications as a free or pedicled flap. Plast Reconstr Surg 1993;92:867-873.

26. Sterne GD, J anuszkiewicz J S, Hall PN, B ardsley AF. The submental Island flap. B rit J Plast Surg 1996;49:85-89.

27. Mathes SJ, Nahai F. Classification of the vascular anatomy of muscles: experimental and clinical correlation. Plast Reconstr Surg 1981;67:177-187.

28. Urken M, M oscoso J, lawson W, et al. A systematic approach to functional reconstruction of the oral cavity following partial and total glossectomy. A rch O tolaryngol Head and N eck Surgery 1994;120:589-614.

29. Urken ML, Okay DJ. Reconstruction of oral cavity following partial and total glossectomy. Multidisciplinary head and neck reconstruction. Lippincott Williams and Wilkins 2010;6: 235-237.

30. Pistre V, Pelissier P, M artin D, Lim A, Baudet J. Ten years of experience with the submental flap. Plast Reconstr Surg 2001; 108:1576-1581. 